Çukurova Üniversitesi Mühendislik Mimarlık Fakültesi Dergisi, 34(2), ss. 197-207, Haziran 2019

Çukurova University Journal of the Faculty of Engineering and Architecture, 34(2), pp. 197-207, June 2019

\title{
Berdan ve Kazanlı (Mersin-Güney Türkiye) Sondajlarının Ostrakod Topluluğu
}

\author{
Ümit ŞAFAK ${ }^{* 1}$ \\ ${ }^{1}$ Çukurova Üniversitesi, Mühendislik Fakültesi, Jeoloji Mühendisliği Bölümü, Adana
}

$\ddot{\mathbf{O} z}$

Geliş tarihi: 01.03.2019 Kabul tarihi: 28.06 .2019

\begin{abstract}
Araştırma, Tarsus ve Mersin yolu üzerindeki Berdan ve Kazanlı civarında yapılan 2 sondaj çalışması üzerinde gerçekleştirilmiştir. Kil, marn, kumtaşı, silttaşı ve killi kireçtaşında yapılan 2 sondajda, Adana Baseni Neojen (Tortoniyen-Erken Pliyosen) birimlerinin stratigrafik ve ortamsal özellikleri çalışılmıştır. İstifin litolojisi ve mikropaleontolojik değerlendirme sonucunda Kuzgun formasyonunda Kazanlı sondajında epineritik koşullarla başlayan ortamsal özelliğin istifin üst seviyelerine doğru acısu özelliğine geçtiği görülmektedir. Berdan sondajında Kuzgun formasyonu alt seviyesinde neritik özellikli ostrakod cinsleri yanında planktonik foraminifer faunası bulunmuştur. Formasyon orta seviyesinde sığlaşma göstererek yer yer acısu koşullarına geçiş göstermektedir. Bu sondajda kesilen Handere formasyonunda ise neritik koşullar belirgindir. Çalışmadaki Kuzgun formasyonu denizel düzeyleri Globoquadrina dehiscens, Globigerinoides trilobus trilobus, G. trilobus sacculifer, G.obliquus obliquus, G.obliquus extremus, Orbulina universa, Dentoglobigerina venezuelana gibi planktonik foraminifer, Cytheridea acuminata neapolitana, C. acuminata acuminata, Loxoconcha rhomboidea, L. turbida, Neomonoceratina mouliana gibi ostrakod türlerini içermektedir. Bu formasyonun acısu özelliği gösteren ostrakod türleri ise Cyprideis seminulum, C. anatolica, C. torosa, C. pannonica'dır. Berdan sondajında kesilen Handere Formasyonu içerisinde ise Carinocythereis carinata, Urocythereis seminulum, Krithe monosteracensis gibi neritik ortamda gözlenen ostrakod türleri bulunmuştur.
\end{abstract}

Anahtar Kelimeler: Kuzgun, Handere, Ostrakod, Neritik ortam, Acısu ortam1, Tarsus

\section{The Ostracod Assemblage of the Berdan and Kazanlı (Mersin-S Turkey) Drillings}

\begin{abstract}
The study was carried out on samples from 2 drillings in the vicinity of Berdan and Kazanli on Tarsus and Mersin road. Stratigraphic and environmental characteristics of the Late Neogene (Tortonian-early Pliocene) units of Adana Basin were studied in 2 drillings made in clay, marl, sandstone, siltstone and clayey limestone. As a result of the lithological and micropaleontological analysis of the sequence, it is seen that the environmental feature, which starts with epineritic conditions in the Kazanli drilling at Kuzgun Formation, passes into the brackish towards the upper levels of the sequence. In the Berdan drilling, planktonic foraminiferal fauna was found in the lower level of Kuzgun Formation along with neritic species of ostracod. The formation shows shallowness at the middle level and shows a transition to brackish conditions. In the Handere Formation which was cut during this drilling, the neritic conditions were significant. Marine horizons of the Kuzgun Formation include ostracod planktonic foraminifera such as Globoquadrina dehiscens, Globigerinoides trilobus trilobus, G.trilobus sacculifer, G.obliquus obliquus, G.obliquus extremus, Orbulina universa, Globigerina venezuelana and ostracod species such as
\end{abstract}

*Sorumlu Yazar (Corresponding Author): Ümit ŞAFAK, usafak@cu.edu.tr 
Cytheridea acuminata neapolitana, Cytheridea acuminata acuminata, Loxoconcha rhomboidea, Loxoconcha turbida, Neomonoceratina mouliana. The ostracod species of this formation indicating the brackish environment are Cyprideis seminulum, Cyprideis anatolica, Cyprideis torosa. In the Handere Formation, the ostracod species observed in the neritic environment such as Carinocythereis carinata, Urocythereis seminulum, Krithe monosteracensis have been determined.

Key words: Kuzgun, Handere, Ostracod, Neritic environment, Brackish environment, Tarsus

\section{GİRİş}

Araştırma Tarsus ve Mersin yöresindeki Berdan ve Kazanlı sondajlarının kil, marn, silt ve kumtaşı seviyelerinden elde edilen mikropaleontolojik veriler üzerinde yapılmıştır (Şekil 1).

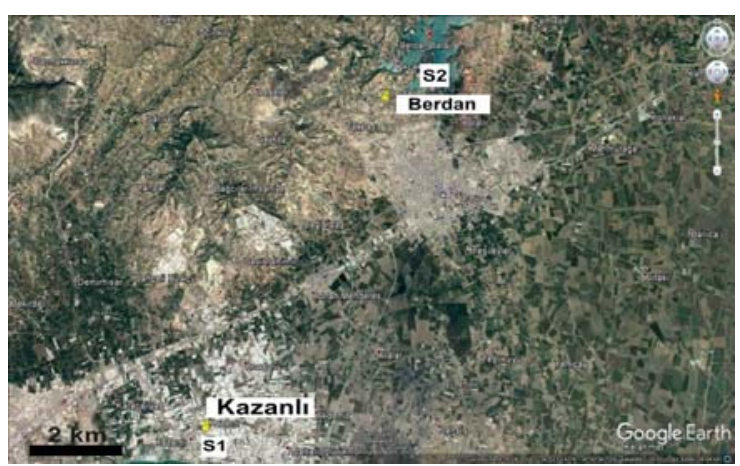

Şekil 1. Çalışma alanının yer bulduru haritası (Google Earth 2016).

Araştırma alanı ve civarında genel jeoloji, paleontoloji, petrol amaçlı çalışmalar yapılmıştır. $[1,2]$ ile başlayan yöredeki bu çalışmalar [3-13,15] ile devam etmiştir.

$\mathrm{Bu}$ çalışmanın amacı, Adana Baseni'nin batı kesiminde, Geç Miyosen-Pliyosen yaş aralığında yüzeylenen Kuzgun ve Handere formasyonlarının stratigrafik ilişkileri ve ortam özellikleri yönünden karşılaştırılmalarını yapabilmektir. $\mathrm{Bu}$ amaç doğrultusunda Berdan ve Kazanlı yerleşim yerlerinde açılan iki sondaj kuyusunun kırıntılı yıkama örnekleri derlenmiş, mikropaleontolojik değerlendirilmesi yapılmıştır. Sondajda kesilen formasyonlardan alınan örneklerde tanımlanan fosil faunaya göre kronostratigrafik ve ortamsal yorum ortaya konulmuştur. Araştırmada iki sondaj (Kazanlı ve Berdan sondajları) incelenmiş, sondajlardan alınan 156 kırıntılı örnekteki ostrakod ve planktonik foraminifer türleri tanımlanmıştır.
Çalışmada ostrakodlardan 36 cins, 78 tür tanımlanmıştır.

\section{MATERYAL VE METOT}

Çalışmada 1/25000 ölçekli Adana $\mathrm{O}_{33} b_{1}$ ve $\mathrm{O}_{33} \mathrm{~b}_{4}$ paftaları kullanılmıştır. Mikropaleontolojik inceleme için arazide bu iki sondajdan alınan kırıntılı yıkama örnekleri işleme tabi tutulmuştur. Bu işlem kırıntılı örnekten 100 gram alınıp, 24 saat \%15'lik hidrojen peroksit $\left(\mathrm{H}_{2} \mathrm{O}_{2}\right)$ eriyiği içerisinde bekletildikten sonra 60, 120, 230 meşlik eleklerden kurulu bir takımla tazyikli su altında yıkanıp ayrıldıktan sonra etüvde kurutulmuş ve elek numaralarına göre ayrı ayrı torbalara konmuştur. Yıkanan örnekler ayıklama tablasında işleme alınmış, tabla içerisinde bulunan mikrofosiller seçilmiştir. Mikrofosil tablasına seçilerek aktarılan bu türler ostrakodlara ağırlık verilerek tanımlanmıştır. 2 sondajdan tanımlanan ostrakod topluluğunda 40 cins, 78 tür bulunmuştur. Fosil cins ve tür ayrımı yapıldıktan sonra bu çalışmada tanımlanan ostrakod ve planktonik foraminiferlerden oluşan 2 adet levha (Levha 1 ve 2) oluşturulmuştur.

Ostrakod cins ve türlerinin tür tayinlerinde ve sistematik tanımlamalar için [16-23]'den yararlanılmıştır. Ostrakod sınıflamasında [24] sınıflaması esas alınmıştır. Tanımlanan cins ve türler sayılmış, ostrakodların yanal ve düşey yayılımları hesaplanmış ve sayısal bollukları belirlenmiştir. Bu dağılım tablosunda ostrakodların frekansını açıklayan simgeler kullanılmıştır. Çok nadir (1-2 kapak) frekanslar + , nadir (3-5 kapak) frekanslar $\square$, yaygın (6-15 kapak) frekanslar $\mathbf{a}, \mathrm{sik}$ (16-25 kapak) frekanslar $\circ$ ve çok sık (>25 kapak) frekanslar - gibi sembollerle gösterilmiştir. İstatiksel ve göreceli değerlendirilen bu veriler baz alınarak, inceleme alanının paleoortam yorumu [16-18,25-27] ortam ve tuzluluk ölçütlerinden yararlanılarak yapılmıştır. 


\section{STRATIGRAFİ}

İnceleme alanında temel birimler Kretase yaşlı Ofiyolit kompleksi [2]'dir. Bu birimler üzerinde Neojen yaşlı Karaisalı, Güvenç, Kuzgun ve
Handere formasyonları uyumsuz olarak yer almaktadır. Araştırma Kuzgun ve Handere formasyonlarında sürdürülmüş olup, bu formasyonların özellikleri açıklanmıştır (Şekil 2).

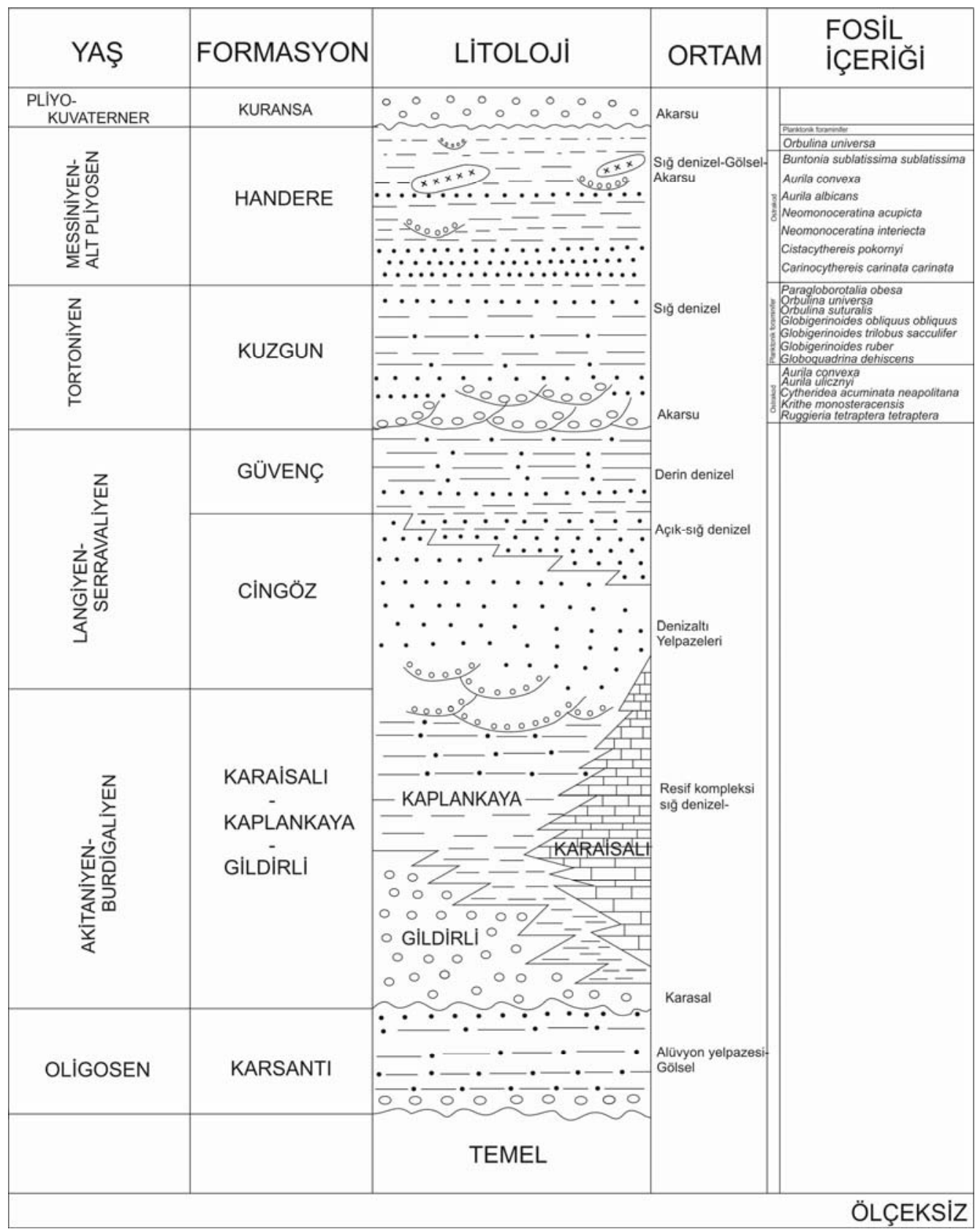

Şekil 2. Çalışma alanının genelleştirilmiş stratigrafi kesiti ([7] ve [14] den yararlanılarak hazırlanmıştır) 


\section{Kuzgun Formasyonu}

İlk kez [2] tarafindan adlandırılan ve 6 üyeye ayrılan birim, [4] tarafindan aynı ad kullanılmış, çalışmacı iki üyeyi benimsemiştir. [6,7] tarafından Kuzgun, Salbaş Tüf ve Memişli üyelerine ayrılarak incelenmiştir. [7] Kuzgun formasyonunun örgülü nehir çökelleri ile sığ denizel çökellerden oluştuğunu; [28] formasyonun sığ deniz ortamında çökeldiğini vurgulamıştır. [15] genel olarak çakıltaşı, çakıllı kumtaşı, silttaşı, kiltaşı killi kireçtaşı ardalanması şeklinde gözlenen formasyonun sı̆̆ denizel özelliğinden bahsetmiş; [11]'da ise çökelme ortamının resif karakterli olduğu kesimlerde ise bol fosilli, yeşilimsi renkli kiltaşı, açık renkli killi kireçtaşı ile iyi boylanma gösteren, sarımsı renkli kumtaşı litolojisinden oluştuğu açıklanmıştır.

Tip lokalitesi Adana Baseni’nde Kuzgun Köyü olan birim, bu araştırmada Berdan ve Kazanlı sondajlarının taban kesimindeki kiltaşı ve silttaşı düzeylerinde gözlenmiştir. Özellikle Berdan sondajında bu birimin üst kesimlerine doğru rastlanılan jips üzerindeki kil düzeyleri acısu karakterli ostrakod faunasını içermektedir. Kazanlı sondajının kil seviyesinde acısu karakterli, killi kireçtaşı seviyelerinde epineritik ortamı yansıtan ostrakod türleri gözlenmiştir.

\section{Handere Formasyonu}

İlk kez [2] tarafindan adlandirılan bu formasyon, Adana Baseni'nde en üst birim olarak ayırtlanmıștır. [10]'in Tarsus kuzeyinde yaptıkları çalışmada, formasyonun Adana Havzası Neojen istifinin daha derin bölümlerini kapsadığını, ilgili çalışmalarında Kuzgun formasyonunun sı̆̆ denizel-akarsu ortamında çökelim gösterirken, Handere formasyonunun denizel ortam özelliği gösterdiğini belirtmişlerdir. Kuzgun formasyonunun Tortoniyen serileri üzerine Handere formasyonunun geçiş-karasal-sı ̆ denizel nitelikli birimlerle geldiği [28] tarafından açıklanmıştır.

Adana Havzası Neojen istifinin daha sı ̆ kesimlerinin incelendiği [29] çalışmasında da bu formasyonun sı̆̆ denizel özellikte olduğu; [30] tarafindan bu formasyonun taban seviyelerinde evaporitik oluşumların (Gökkuyu Alçıtaşı Üyesi) bulunduğu belirtilmiştir.

Tip lokalitesi Adana Baseni'nde Handere Köyü olan birim, bu araştırmada Berdan ve Kazanlı sondajlarının üst kesimindeki silttaşı, kiltaşı ve killi kireçtaşı düzeylerinde gözlenmiştir. Çalışmada birimde evaporit seviyesine rastlanmamıştır.

Yer yer batiyal ortama dek gözlenebilir ölçekte derin, genellikle neritik özellikte denizel karakterli ostrakod topluluğu içeren birim, Berdan sondajında $162 \mathrm{~m}$ gibi daha belirgin kalınlık sunmaktadir.

\section{INCELEME ALANI SONDAJ VERILERI}

\subsection{Kazanlı (Mersin) S1 Sondajı}

1/25000 ölçekli Adana $\mathrm{O}_{33} \mathrm{~b}_{4}$ paftasında, $36^{0} 49^{\prime} 17.46$ " $\mathrm{K}$ ve $34^{0} 45^{\prime} 42.62$ 'D koordinatlarında yer alan bu sondaj $140 \mathrm{~m}$ derinlikli olup tabandan yukarı doğru Kuzgun formasyonu ile Kuvaterner kaliçi düzeyinden oluşmaktadır.

Sondajda yaklaşık 45 m'de Kaliçi birimi, 46-140 m'ler arasında Kuzgun formasyonu kesilmiştir.

İstifte Kuzgun formasyonu mavi renkli kil, marn ve kireçtaşı bantlı kil, marn arabantlı kireçtaşı, kireçtaşı ve marn düzeylerini içermektedir. Üzerinde uyumsuz olarak kumlu-çakıllı kil, kumlu kil ve çakıllı kum düzeylerinden oluşan kaliçi birimi yer almaktadır.

İstifin tabanında ölçülen Kuzgun formasyonunun kilden oluşan taban düzeylerinde Cyprideis torosa, Cyamocytheridea obstipa, $C$. meniscus, $C$. polygona gibi lagün; üzerindeki killi kireçtaş1 seviyelerinde Orbulina universa gibi planktonik foraminifer yanında Thalmannia procera, $T$. clauda, Heterocythereis albomaculata, A. convexa, Loxoconcha rhomboidea, Xestoleberis communis; 
orta-üst düzeylerinde Neomonoceratina interiecta, Schneidrella dromas, Aurila freudenthali, Tenedocythere salebrosa, Xestoleberis ventricosa, Argilloecia conoidea; sik ve çok sik frekansta formasyonun tüm düzeylerinde tayin edilen Aurila ulicznyi gibi neritik ortam koşullarına uyumlu ostrakod türleri tanımlanmıştır (Şekil 3).

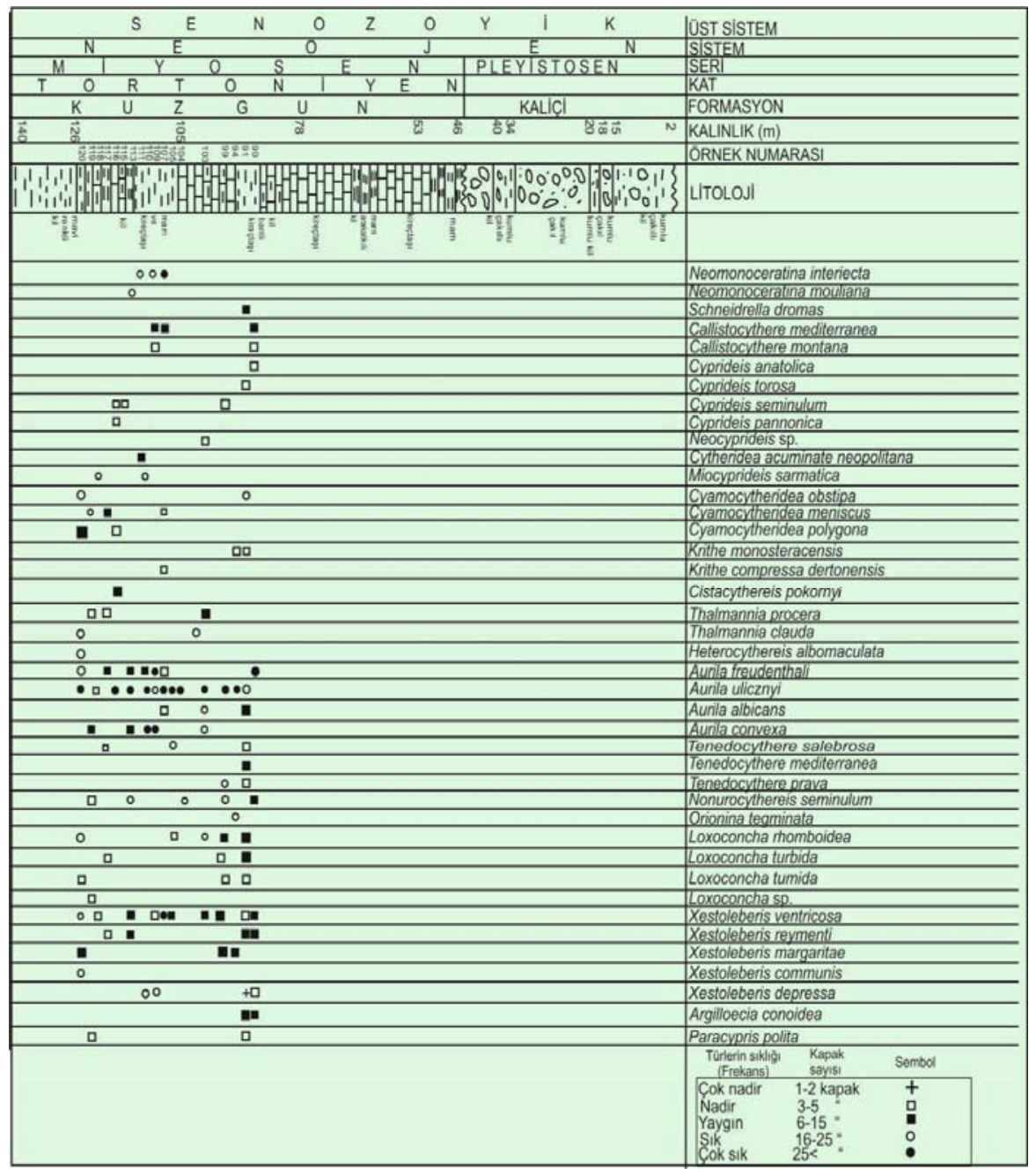

Şekil 3. Kazanlı (Mersin) sondajında ostrakod cins ve türlerinin dağılımı

\subsection{Berdan (Tarsus) S2 Sondajı}

1/25000 ölçekli Adana $\mathrm{O}_{33} \mathrm{~b}_{1}$ paftasında, $37^{0} 57^{\prime} 16.22^{\prime \prime} \quad \mathrm{K}$ ve $34^{0} 51^{\prime} 21.80^{\prime}$ 'D koordinatlarında yer alan bu sondaj $200 \mathrm{~m}$ derinlikli olup tabandan yukarı doğru Kuzgun ve Handere formasyonları ile Kuvaterner yaşlı çakı1 ve kum karışımlı düzeylerden oluşmaktadır.
Sondajla ölçülen 40 m kalınlıklı Kuzgun birimi taban ve orta düzeylerinde kiltaşı, silttaşı ve üst seviyelere doğru jips ve kil litolojisine geçmektedir. Jips üzerindeki 28 nolu örneğin killi seviyeleri Cyprideis seminulum, $C$. anatolica ve $C$. torosa gibi acısu; altındaki kiltaşı, silttaşı seviyeleri ise Neomonoceratina mouliana, epineritik özellikli Cytherella sordida, 
Carinocythereis antiquata, Aurila soummamensis, A. convexa, Xestoleberis vetricosa gibi, neritik ortam karakteri gösteren ostrakod cins ve türlerini içermektedir. Ayrıca istifte Handere formasyonu içerisindeki 1 nolu örnekte Orbulina universa; Kuzgun formasyonu içerisindeki 33 nolu örnekte Orbulina suturalis, Globigerinoides trilobus trilobus; 35 nolu örnekte Orbulina universa, O. suturalis, Globoquadrina dehiscens, Globigerinoides trilobus trilobus, G. trilobus sacculifer, G. ruber, G.obliquus obliquus, G.obliquus extremus, Dentoglobigerina venezuelana, Dentoglobigerina altispira, Catapsydrax dissimilis gibi; 36 nolu örnekte Orbulina universa, Globigerinoides trilobus trilobus, G. trilobus sacculifer, Globigerina venezuelana, G.obliquus obliquus, Paragloborotalia obesa gibi planktonik foraminifer türleri tanımlanmıştır. Sondajın 40-145 m'ler arası, üst seviyelerindeki diğer birimi olan Handere Formasyonu silttaş1-kiltaş1-killi kireçtaşı litolojisi ile baskın olup, istif yeşilimsi renkli kiltaşı ve silttaşı bantları ile sona ermektedir.

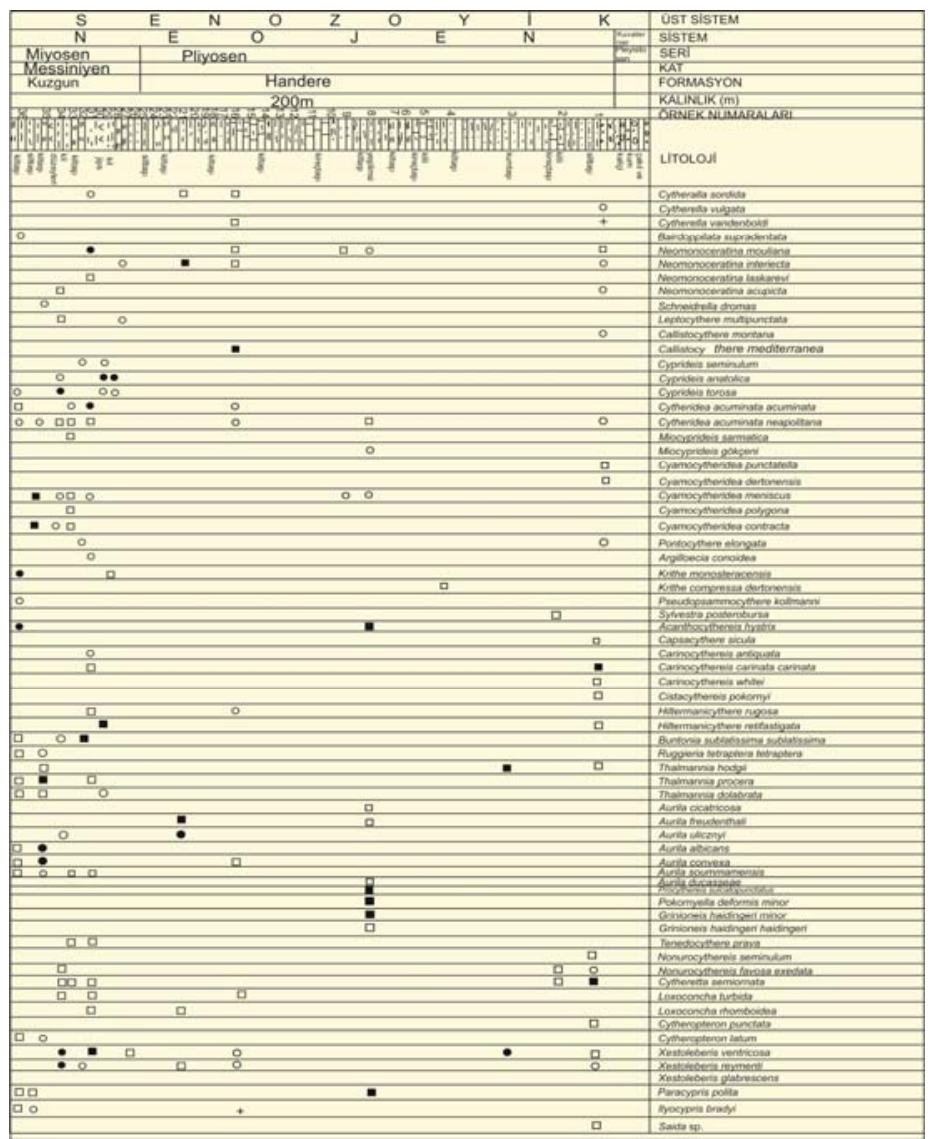

Şekil 4. Berdan (Tarsus) sondajında ostrakod cins ve türlerinin dağılımı

Formasyonun taban düzeylerinde Cytherella sordida, Neomonoceratina interiecta; orta kesimlerinde Callistocythere mediterranea, Cytheridea acuminata acuminata, Costa edwardsii, Aurila freudenthali, Xestoleberis glabrescens; üst kesimlerde Cytheridea acuminata neapolitana, Cyamocytheridea punctatella, $C$. dertonensis, Carinocythereis carinata carinata, Cistacythereis pokornyi, Urocythereis seminulum, Cytheropteron punctatum gibi neritik özellikli zengin ostrakod faunası tanımlanmıştır (Şekil 4) (Çizelge 1). 
Çizelge 1. İnceleme alanı ostrakod cinslerinin yansıttıkları ortamlar [17]

\begin{tabular}{|c|c|c|c|c|c|c|}
\hline OSTRACODA & :ટ્ડ & 咅 & 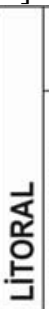 & 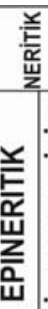 & & 㐫 \\
\hline CYTHERELLA & & & & & & \\
\hline BAIRDOPPILATA & & - & & & & \\
\hline NEOMONOCERATINA & & & & & & \\
\hline SCHNEIDERELLA & & & & & & \\
\hline LEPTOCYTHERE & & - & - & & & \\
\hline CALLISTOCYTHERE & & & & & & \\
\hline CYPRIDEIS & & - & & & & \\
\hline NEOCYPRIDEIS & & 0 & & & & \\
\hline CYTHERIDEA & & & & & & \\
\hline MIOCYPRIDEIS & & & & & & \\
\hline CYAMOCYTHERIDEA & & - & & & & \\
\hline PONTOCYTHERE & & & & & & \\
\hline ARGILLOECIA & & & & & & - \\
\hline KRITHE & & & & & & \\
\hline PSEUDOPSAMMOCYTHERE & & & & & & \\
\hline SYLVESTRA & & - & - & & & \\
\hline ACANTHOCYTHEREIS & & & - & & & \\
\hline CAPSACYTHERE & & & & & & \\
\hline CARINOCYTHEREIS & & & & E & & \\
\hline CISTACYTHEREIS & & & - & E & & \\
\hline HILTERMANICYTHERE & & & & & & \\
\hline BUNTONIA & & - & & & & \\
\hline RUGGIERIA & & & & & & \\
\hline KEIJELLA & & & 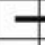 & - & & \\
\hline HETEROCYTHEREIS & & & & & & \\
\hline AURILA & & & & & & \\
\hline PROCYTHEREIS & & & & & & \\
\hline POKORNYELLA & & & & & & \\
\hline GRINIONEIS & & & & & & \\
\hline TENEDOCYTHERE & & & & - & & \\
\hline UROCYTHEREIS & & & & - & & \\
\hline ORIONINA & & & & - & & \\
\hline CYTHERETTA & & & & - & & \\
\hline LOXOCONCHA & & & & & & \\
\hline CYTHEROPTERON & & & & & & \\
\hline XESTOLEBERIS & & & & & & \\
\hline PARACYPRIS & & & & & & \\
\hline $\begin{array}{l}\text { ILYOCYPRIS } \\
\text { SAIDA }\end{array}$ & & & & & & \\
\hline
\end{tabular}

\section{SONUÇLAR VE TARTIŞMA}

İnceleme alanı, Mersin il sınırları içerisindeki Kazanlı ile Tarsus İlçesi'ne bağlı Berdan yerleşim bölgesinde açılmış 2 sondajın bulunduğu kesimdir. Araştırma, Tarsus ve Mersin yolu üzerindeki Berdan ve Kazanlı civarında yapılan bu 2 sondaj çalışması üzerinde gerçekleştirilmiştir.

İncelenen ve killi-kireçli, siltli birimlere ağırlık verilerek irdelenen litolojilerden, Handere ve Kuzgun formasyonları ile Kaliçi biriminin varlığı gözlenmiştir. Bu birimler Adana Baseni'nde yer alan ve Tortoniyen-Pliyosen aş aralığında çökelmiş, geniş yayılımlı birimlerdir. $\mathrm{Bu}$ çalışmada tanımlanan Neomonoceratina interiecta, N. mouliana, Cytheridea acuminata neapolitana, Krithe monosteracensis, Aurila ulicznyi, Xestoleberis compressa türlerinin kronostratigrafik düzeyleri ile Sissingh [18] ile Bonaduce ve arkadaşlarının [23] çalışmasındaki aynı türlerin Tortoniyen-Pliyosen düzeyleri Cyamocytheridea polygona, C. meniscus türlerinin stratigrafik düzeyleri ile Doruk [19] çalışmasındaki aynı türlerin Tortoniyen düzeyleri Cyprideis torosa, C.seminulum, C. pannonica türlerinin kronostratigrafik düzeyleri ile Bassiouni [20] çalışmasındaki aynı türlerin Üst Miyosen düzeyleri yakın benzerlik göstermektedir. $\mathrm{Bu}$ araştırmada Kuzgun ve Handere formasyonlarının denizel, sı $\breve{g}$ denizel, litoral özellik yanısıra lagüner karakterli fauna özelliği gösteren zengin bir mikrofosil topluluğuna sahip oldukları görülmüştür. 2 sondajın örneklerinin incelenmesi ile Kazanlı sondajında Kuzgun formasyonunun marn ve kireçtaşı bantlı kil ile kil bantlı kireçtaşları içerisinden alınan;

Berdan sondajında kiltaşı-silttaşı ve jips alt-üst seviyesindeki kil düzeylerinden alınan yıkama örneklerinde zengin ostrakod cins ve türleri tanımlanmıştır.

Berdan sondajinda ise Handere formasyonunun özellikle kiltaşı ve silttaşı seviyelerindeki yıkama örneklerinde zengin ostrakod cins ve türleri yer almaktadır. Kuzgun formasyonunun taban seviyelerindeki kil ve kiltaşları genellikle 
epineritik derinlikte ostrakod cinsleri ile birlikte Globoquadrina dehiscens, Globigerinoides trilobus trilobus, G. trilobus sacculifer, G. ruber, G.obliquus obliquus, G.obliquus extremus, Dentoglobigerina venezuelana, Dentoglobigerina altispira, Catapsydrax dissimilis gibi planktonik foraminifer faunası içermektedir. Ayrıca jips üzerindeki killi seviyeler de zaman zaman sığlaşmıș, Cyamocytheridea, Loxoconcha gibi lagün-litoral nitelik kazanan ostrakod cinsleri Neomonoceratina, Ruggeria, Thalmannia, Aurila, Pokornyella, Tenedocythere, Urocythereis, Cytheretta gibi genellikle epineritik karakterli cinsler yanında gözlenmiştir. Handere formasyonunda ise epineritik-infraneritik ve batiyal ortam özelliğine uyumlu Cytherella, Neomonoceratina, Cytheridea, Cyamocytheridea, Pontocythere, Krithe, Aurila, Grinioneis, Cytheropteron, Xestoleberis, Paracypris gibi ostrakod topluluğu bulunmuştur.

Kuzgun formasyonunun Tortoniyen içerisindeki zaman zaman Ilyocypris, Loxoconcha gibi ostrakod cinsleri ile belirginleşen lagüner karakterinin baskınlığı sonrasında, üzerinde yer alan Handere formasyonunun, Orbulina universa ile belirgin planktonik foraminifer faunası içermiş olmasına rağmen, alttaki birime göre daha derin bir deniz ortamında çökelmiş olduğunu göstermektedir.

Çalışmada Bairdoppilata supradentata, Schneidrella dromas, Cyprideis anatolica, $C$. torosa, C. pannonica, Miocyprideis sarmatica, Cyamocytheridea polygona, C. contracta, Krithe monosteracensis, $K$. citae, Carinocythereis antiquata, Cistacythereis pokornyi, Buntonia sublatissima sublatissima, Ruggieria tetraptera tetraptera, Thalmannia procera, T. dolabrata, $T$. clauda, Aurila ulicznyi, A. albicans, A. convexa, A. soummamensis, Tenedocythere prava, $T$. salebrosa, T. mediterranea, Orionina tegminata, Loxoconcha tumida, L. turbida, L. rhomboidea, Xestoleberis margaritae, $X$. depressa, Paracypris polita, Ilyocypris bradyi Kuzgun Formasyonu taban, orta ve üst seviyelerinde;

Cytherella vulgata, Cyamocytheridea dertonensis, C. meniscus, Sylvestra posterobursa, Capsacythere sicula, Thalmannia hodgii, Cytheropteron punctatum Handere Formasyonu içerisinde belirlenmiş ostrakod türleridir.

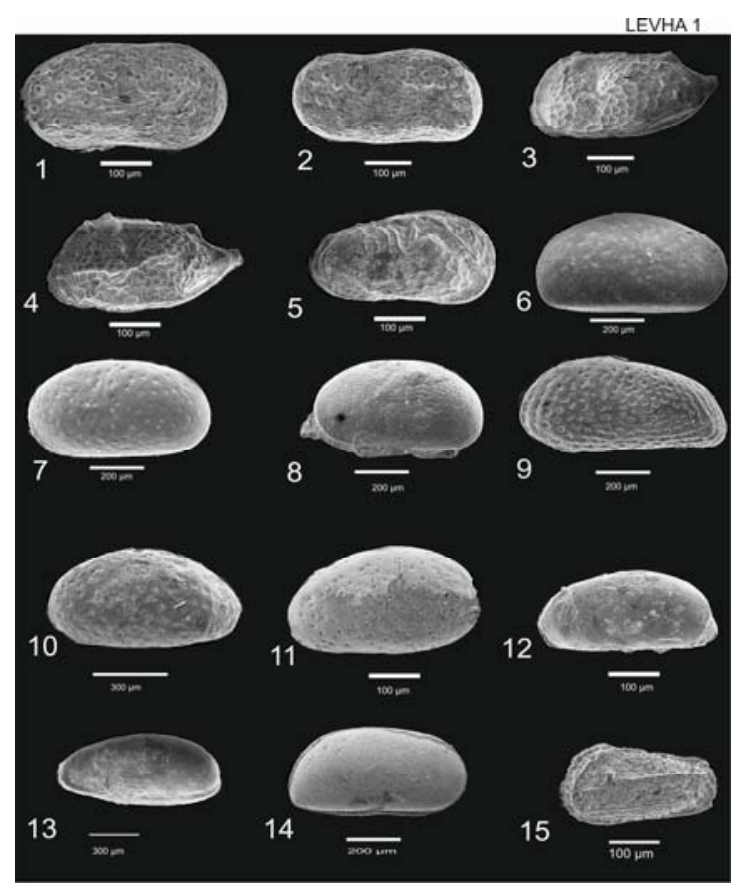

\section{Levha 1}

\section{Foto 1-2 Cytherella sordida (Müller)}

1. Sağ kapak, yan görünüm, Berdan sondaj1, 31 nolu örnek

2. Sol kapak, yan görünüm, Kazanlı sondaj1, 94 nolu örnek

Foto 3-4. Neomonoceratina mouliana Sissingh

3. Kabuk, sol dış görünüm, Kazanlı sondaj1, 113 nolu örnek

4. Kabuk, sol dış görünüm, Berdan sondaj1, 31 nolu örnek

Foto 5. Callistocythere montana Doruk

5. Kabuk, sağ yan görünüm, Kazanlı sondajı, 90 nolu örnek

Foto 6. Cyprideis torosa (Jones)

6. Sağ kapak, yan görünüm, Kazanlı sondajı, 90 nolu örnek

Foto 7. Cyprideis seminulum (Reuss))

7. Sağ kapak, yan görünüm, Kazanlı sondajı, 116 nolu örnek

Foto 8. Cyprideis pannonica (Mehes) 
8. Sol kapak, dış görünüm, Kazanlı sondajı, 116 nolu örnek

Foto 9. Cytheridea acuminata acuminata Bosquet

9. Sol kapak, yan görünüm, Berdan sondaj1, 34 nolu örnek

Foto 10. Cyamocytheridea obstipa Doruk

10. Kabuk, sağ dış görünüm, Kazanlı sondajı, 126 nolu örnek

Foto 11. Cyamocytheridea meniscus Doruk

11. Sol kapak, yan görünüm, Kazanlı sondajı, 99 nolu örnek

Foto 12-13. Pontocythere elongata (Brady)

12. Kabuk, sol diș görünüm, Berdan sondajı, 33 nolu örnek

13. Kabuk, sol diş görünüm, Berdan sondajı, 1 nolu örnek

Foto 14. Krithe citae Oertli

14. Kabuk, sağ dış görünüm, Kazanlı sondajı, 105 nolu örnek

Foto 15. Costa edwardsii (Roemer)

15. Sağ kapak, yan görünüm, Berdan sondajı, 16 nolu örnek

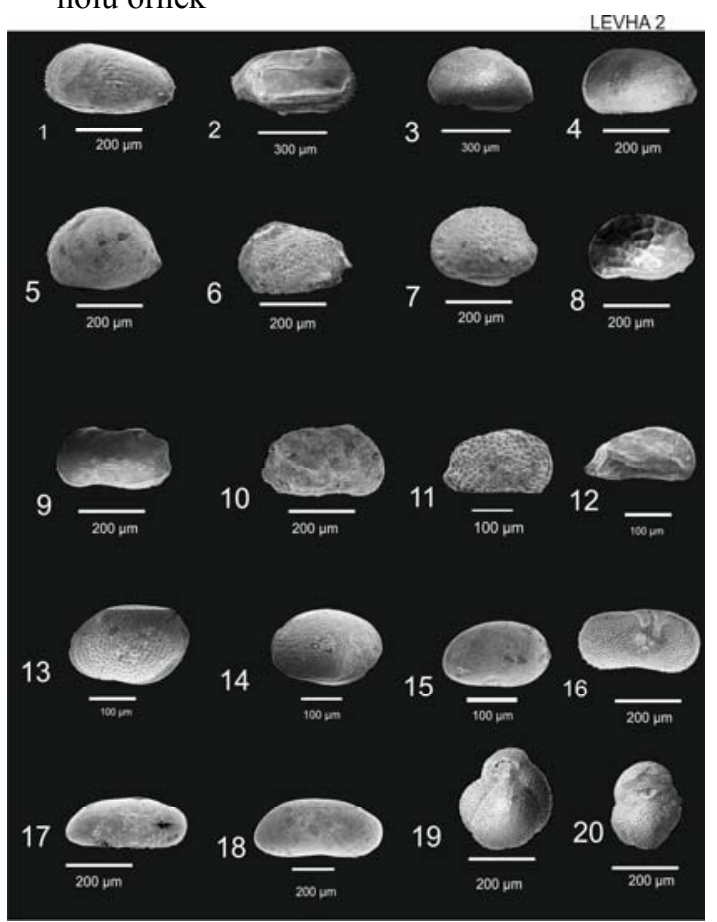

Levha 2

Foto 1. Thalmannia hodgii (Brady)
1. Sol kapak, yan görünüm, Berdan Sondajı, 36 nolu örnek

Foto 2. Ruggieria tetraptera tetraptera Sequenza

2. Kabuk, sağ dış görünüm, Berdan Sondajı, 36 nolu örnek

Foto 3. Aurila ducasseae Moyes

3. Kabuk, sol diş görünüm, Berdan sondajı, 8 nolu örnek

Foto 4. Aurila freudenthali Sissingh

4. Sol kapak, yan görünüm, Berdan sondaj1, 8 nolu örnek

Foto 5. Aurila speyeri (Brady)

5. Sol kapak, yan görünüm, Berdan sondajı, 36 nolu örnek

Foto 6. Procythereis sulcatopunctatus (Reuss)

6. Sol kapak, yan görünüm, Berdan sondaj1, 8 nolu örnek

Foto 7. Pokornyella deformis minor (Moyes)

7. Kabuk, sol diş görünüm, Berdan sondajı, 8 nolu örnek

Foto 8. Tenedocythere salebrosa Uliczny

8. Sol kapak, yan görünüm, Kazanlı sondajı, 116 nolu örnek

Foto 9. Grinioneis haidingeri haidingeri (Reuss)

9. Kabuk, sol dış görünüm, Berdan sondajı, 8 nolu örnek

Foto 10. Grinioneis haidingeri minor Ruggieri

10. Kabuk, sağ dış görünüm, Berdan sondajı, 8 nolu örnek

Foto 11. Urocythereis favosa exedata Uliczny

11. Sağ kapak, yan görünüm, Berdan sondajı, 2 nolu örnek

Foto 12. Orionina tegminata Doruk

12. Kabuk, sağ dış görünüm, Kazanlı sondajı, 94 nolu örnek

Foto 13. Loxoconcha rhomboidea (Fischer)

13. Kabuk, sol dış görünüm, Kazanlı sondajı, 91 nolu örnek

Foto 14. Loxoconcha turbida Müller

14. Kabuk, sol dış görünüm, Kazanlı sondajı, 91 nolu örnek

Foto 15. Xestoleberis margaritae Müller

15. Kabuk, sol dış görünüm, Kazanlı sondajı, 95 nolu örnek

Foto 16. Ilyocypris bradyi Sars

16. Sağ kapak, yan görünüm, Berdan sondaj1, 16 nolu örnek

Foto 17-18. Argilloecia conoidea Sars 
17. Sağ kapak, yan görünüm, Kazanlı sondajı, 91 nolu örnek

18. Sağ kapak, yan görünüm, Kazanlı sondajı, 90 nolu örnek

Foto 19. Globigerinoides obliquus extremus Bolli \& Bermudez

19. Karından görünüm, Kazanlı sondajı, 111 nolu örnek

Foto 20. Globigerinoides obliquus obliquus Bolli

20. Karından görünüm, Kazanlı sondajı, 113 nolu örnek

\section{KATKI BELİRTME}

Bu çalışmanın SEM çekimleri FBA-2017-9897 nolu Ç:Ü. BAP projesi tarafından desteklenmiştir. Yazar araştırmanı sondaj verilerini sağlayan MES Jeofizik Araştırmalar Laboratuvar Sorumlusu Sayın Mehmet GÜZEL ve Sayın Dr. Muzaffer ŞENOL'a, araştırmanın çizim aşamalarında yardımcı olan Sayın Dr. Nusret NURLU'ya (Ç.Ü), ostrakod fotoğraflarının SEM çekimlerini gerçekleştiren Çukurova Üniversitesi Merkezi Araştırma Laboratuvarı (ÇÜMERLAB)'na, teşekkür eder.

\section{KAYNAKLAR}

1. Ternek, Z., 1957. Adana Havzasının Alt Miyosen (Burdigaliyen) Formasyonlar1; Bunların Diğer Formasyonlarla Olan Münasebetleri ve Petrol İmkanları. MTA Der., 49, 48-66.

2. Schmidt, G.C., 1961. Stratigraphic Nomenclature for the Adana Region Petroleum District., 7. Petroleum Administration Bull., 6, 47-63, Ankara.

3. Öztümer, E., Bizon, G., Bizon, J.J., Feinberg, H., 1974. Mut ve Adana Havzaları Tersiyer Biyostratigrafisi ve Mikropaleontoloji yenilikleri. Türkiye II-Petrol kong. Tebliğleri, 217-228.

4. İlker, S., 1975. Adana Baseni kuzeybatısının Jeoloji ve Petrol Olanakları, T. P. A. O. Arama arşiv No: 973, Ankara.

5. Tanar, Ü., 1985. Körlü (Tarsus-Mersin) Bölgesi 'Karaisalı, Kuzgun, Memişli'"
Formasyonlarının Molluska Faunası, Jeoloji Müh. Dergisi, 24, 17-31, Adana.

6. Yetiş, C., Demirkol, C., Kerey, E., 1986. Adana Havzasının Kuzgun Formasyonunun (Üst Miyosen) Fasiyes ve Ortamsal Nitelikleri. T. J. K. Bülteni, 29. 81-96

7. Yetiş, C., Demirkol, C., 1986. Adana Baseni Batı Kesiminin Detay Jeolojik Etüdü, MTA Rapor No:8037, 187s., Ankara.

8. Yetiş, C., 1988. Yetiş, C., 1988. Reorganisation of the Tertiary Stratigraphy in the Adana Basin, Southern Turkey. Newsletter Stratigraphy, 20(1), 43-58.

9. Ünlügenç, U.C., Kelling, G., Williams, G.D., Demirkol, C., 1990. Aspects of Basin Evolution in the Neogene Adana Basin, SE Turkey, International Earth Sciens Congress on Aegean Regions (IESCA), 1-6 October, Edit: Savaşçın, M.Y. and Eronat, A.H., 353-369, İzmir.

10. Şafak, Ü., Nazik, A., 1994. Eshab-1 Kehf (Tarsus-Mersin) dolay1 Neojen istifinin ortamsal yorumu, Ç.Ü. Yerbilimleri Dergisi, 15. Y1l Sempozyumu, 291-300, Adana.

11. Şafak, Ü., Ünlügenç, U.C., Şenol, M., 1996, İncirlik (Adana güneydoğusu) çevresinde yeralan Geç Miyosen resifinin stratigrafisi ve mikropaleontolojisi, T.J.K. Bülteni, 11, 138-153, Ankara.

12. Korkmaz, A., 2000. Huzurkent (Tarsus) Civar1 Neojen İstifinin Mikropaleontolojik Özellikleri ve Ortamsal Yorumu, Ç.Ü. Fen Bilimleri Ens. Yüksek Lisans Tezi, 146, 8 lev., Adana.

13. Öğrünç, G., 2001. Messiniyen Tuzluluk Krizi Sırasındaki ve Sonrasındaki Çökellerin Stratigrafisi ve Paleoekolojisi. Bir Örnek: Adana Baseni, Ç.Ü. Fen Bilimleri Ens. Doktora Tezi, 218, 9lev., Adana.

14. Avşar, N., Nazik, A., Dinçer, F., Darbaş, G., 2006, Adana Havzası Kuzgun Formasyonunun Mikro Fosiller ile Ortamsal Yorumu, Hacettepe Yerbilimleri Dergisi, 27(1), 1-21.

15. Şafak, Ü., Heybeli, D., 2008, Huzurkent (Tarsus) Civarındaki Kuzgun Formasyonu'nun Ostrakod Toplulukları ve Ortamsal Özellikleri, Yerbilimleri (Geosound), Prof. Dr. Servet Yaman Özel Sayıs1, Sayı 52, 225-247, Adana.

16. Morkhoven, F.P.T., 1962. Post Paleozoic Ostracoda, Elsevier edit., 1:1-244. 
17. Morkhoven, F.P.T., 1963, Post Paleozoic Ostracoda, Elsevier edit., 2:1-478.

18. Sissingh, W., 1972, Late Cenozoic Ostracode of the South Aegean Island, Arc.Bull. Utrecht. Micropaleont., 6, 1-187.

19. Doruk, N., 1973. A Stereo-atlas of Ostracod Shells, Puplished by the Department of Geology in the University of Leicester, Volume 1, Part 1, England.

20. Bassiouni, M.A., 1979. Brackische und Marine Ostrocoden (Cytherideinae, Hemicytherinae, Trachyleberidinae) aus dem Oligozaen und Neogen der Turkei, Geol. Jb. Reihe B, Heft 31, Hannover, 1-200.

21. Yassini, I., 1979. The Littoral System Ostracodes from the Bay of Bou-İsmail, Algiers, Algeria., National Iranian Oil Company, Revista Espanoia de Micropaleontologia, XI(3), 353-416, Tehran, Iran.

22. Oertl1 H.J., 1985. Atlas des Ostracodes de France. Bulletin Centres Rechearche Exploration Proceeding Elf-Aquitaine. Mémoire, 9, 257-335.

23. Bonaduce, G., Ruggieri, G., Russo, A., Bismuth, H., 1992. Late Miocene from the Ashtart 1 well (Gulf of Gabes, Tunisia), Bollettino della Societa Paleontologica İtaliana, 31 (1), 3-93, 26 pls, Modena.

24. Hartmann, G., Puri, H., 1974, Summary of Neontological and Paleontological Classification of Ostracod. Mitt. Hamburg Zool. Must. Inst., 20, 7-73

25. Stambolidis, E.A., 1985, Zur Kenntnis der Ostracoden des Evros Delta (Nord-Agaisches Meer) Griechenland, Mitt. Hamb. Zool. Mus. Inst., Band 82, 155-254.

26. Athersuch, J., Horne, D.J., Whittaker, J.E., 1989. Marine and Brackish Ostracods, Synopsesof the British Fauna (N.S.), 43.

27. Remane, A., 1958. Die Biologie des Brackwassers. In: THIENEMANN, A: Die Binenge wasser, Einzeldarstellungen aus der Limnologie und ihren Nachbargebieten,

28. Öğrünç, G., Nazik, A., 1998. Yenice (Tarsus) kuzeyi (Adana Havzası) Üst Miyosen-Pliyosen istifinin ostrakod faunası. Türkiye Jeoloji Bülteni, 41 (1), 63-84.
29. Darbaş, G., Nazik, A., 2010. Micropaleontology and Paleoecology of the Neogene Sediments in the Adana Basin (South of Turkey). Journal of Asian Earth Sciences. 39(3), 136-147.

30. Öğrünç, G., 1996. Yenice (Tarsus) Kuzeyi Neojen İstifinin Mikropaleontolojik İncelenmesi ve Ortamsal Özellikleri, Ç.Ü. Fen Bilimleri Ens. Yüksek Lisans Tezi, 115s., 5lev., Adana. 
